МОРФОЛОГИЯ СЛИЗИСТОЙ ОБОЛОЧКИ ЖЕЛУДКА, КОНТАМИНИРОВАННОЙ ХЕЛИКОБАКТЕРОМ, КРИПТОСПОРИДИЯМИ И ГРИБАМИ РОДА САNDIDA У ПАЦИЕНТОВ С СИНДРОМОМ РАЗДРАЖЕННОГО КИШЕЧНИКА

Щербаков И.Т.', Леонтьева Н.И.' ${ }^{1}$, Грачева Н.М. ${ }^{1}$, Филиппов В.С. ${ }^{1}$, Виноградов Н.А. ${ }^{2}$, Филиппова O.A. ${ }^{3}$

Московский Научно-исследовательский институт эпидемиологии и микробиологии им. Г.Н. Габричевского, Москва, Россия; Российский национальный исследовательский медицинский университет им. Н.И. Пирогова, Москва, Россия; Инфекционная клиническая больница № 1 Департамента здравоохранения Москвы, Москва, Россия

\title{
THE MORPHOLOGY OF THE MUCOUS MEMBRANE OF THE STOMACH AT THE ITS CONTAMINATION OF HELICOBACTER, CRYPTOSPORIDIUM AND FUNGI OF THE SPECIES CANDIDA IN PATIENTS WITH IRRITABLE BOWEL SYNDROME
}

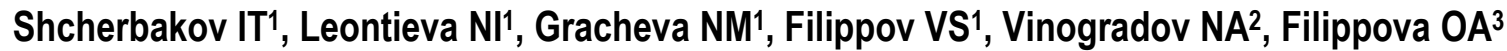

${ }^{1}$ Epidemiology\&Microbiology Research Intuition name of GN Gabrichevskii, Moscow, Russia; ${ }^{2}$ Russian State Research Medical University name of NI Pirogov, Moscow, Russia; ${ }^{3}$ Clinical Infection Hospital № 1 of the Health Department of Moscow, Moscow, Russia

\section{DOI: 10.20340/mv-mn.17(25).01.03}

Щербаков И.Т., Леонтьева Н.И., Грачева Н.М., Филиппов В.С., Виноградов Н.А., Филиппова О.А. Морфология слизистой оболочки желудка, контаминированной хеликобактером, криптоспоридиями и грибами рода Сапdida у пациентов с синдромом раздраженного кишечника// Морфологические Ведомости.- 2017.- Том 25.- № 1.- С. 15-19

Резюме. Общепризнана ведущая роль пилорического хеликобактера в этиологии и патогенезе заболеваний желудочно-кишечного тракта, установлены морфологические особенности изменений в слизистой оболочке при моноинфекции. Однако поражения желудка могут носить смешанный инфекционный характер, изменяя течение основного заболевания. Цель исследования - изучить состояние слизистой оболочки при её контаминации пилорическим хеликобактером, грибами рода Candida, криптоспоридиями у пациентов с синдромом раздраженного кишечника. Изучены биоптаты слизистой оболочки разных отделов желудка с использованием стандартных методов окраски с дальнейшей оценкой полученных результатов. Патоморфологические изменения слизистой оболочки желудка зависели от локализации процесса, степени контаминации и наличия разных жизненных форм пилорического хеликобактера, тогда как криптоспоридии и грибы рода Candida (неинвазивные формы) существенного влияния на морфологию слизистой желудка не оказывали.

Ключевые слова: слизистая оболочка желудка, биоптат, адаптация, морфологический анализ

Summary. It is recognized the leading role of H. Pylori in the etiology and pathogenesis of diseases of the gastrointestinal tract, it is established morphological features of changes in the mucosa at mono-infection. However, lesions of the stomach may have mixed infectious character, changing the course of the main disease. The aim of research is to investigate the statement of the mucous membrane in its contamination with H. Pylori, Fungi of the species Candida, cryptosporidium in patients with irritable bowel syndrome. Biopsies of the mucous membrane of different stomach parts were studied, using conventional methods of dyeing with further evaluation of the results. Pathological changes in the stomach mucosa were depended on the localization of the process, the measure of contamination, and the presence of various life forms of pyloric Helicobacter whereas cryptosporidium and fungi of the species Candida (non-invasive form) did not influence essentially.

Key words: gastric mucosa, biopsy, adaptation, morphological analysis

Введение. Ведущая роль Helicobacter pylori (HP) - инфекции в этиологии и патогенезе воспалительных заболеваний желудка и 12-типерстной кишки (ДПК) доказана и признана всем научно-клиническим сообществом. Убедительным свидетельством этого является присуждение Нобелевской премии 2005 года по физиологии и медицине, австралийским исследователям B.J. Marshall и J.R. Warren «за открытие бактерии Helicobacter pylori и ее роли в развитии гастрита и пептической язвы желудка». В настоящее время является доказанным факт участия НР в возникновении рака желудка и MALT-лимфомы желудка, изучена морфология микроорганизма, полиморфизм штаммов, установлен геном. Широкое распространение НP в мире обусловлено его способностью к рекомбинантным мутациям и возможностью существования в кислой среде желудка, что позволяет выжить в неблагоприятных условиях. При этом известно, что большинство хронических заболеваний желудочно-кишечного тракта (ЖКТ), ассоциированных с НР-инфекцией, протекают в виде смешанного инфекционного патологического процесса с утяжелением течения сочетанного заболевания. Исследования последних лет [1-5] показали, что в слизистой оболочке желудка (СОЖ), помимо НР, могут совместно существовать и другие микроорганизмы (вирусы - ВПГ І-ІІ тип, ВЭБ, ЦМВ, простейшие, например, криптоспоридии, грибы рода Candida). Такое сосуществование нескольких микроорганизмов в одной экологической нише и влияние сочетанной инфекции на характер морфологических изменений в СОЖ до настоящего времени изучено недостаточно.

Цель работы - изучить по биоптатам состояние слизистой оболочки разных отделов желудка при ее контаминации пилорическим хеликобактером, криптоспоридиями, грибами рода Candida у пациентов с синдромом раздраженного кишечника.

Материал и методы. Под наблюдением находилось 30 пациентов обоего пола (мужчины - 10, женщины - 20) с предварительным диагнозом «синдром раздраженного кишечника», от которых при эзофагогастродуоденоскопии (ЭГДС) были получены 72 биоптата слизистой оболочки желудка. Средний возраст пациентов составил 51,5 лет. Исследования проводились по протоколу согласно требованиям этического комитета и с письменного согласия пациентов.

Пациентам были проведены комплексные клинико-лабораторные исследования: традиционные клинические, бактериологические, паразитологические, инструментальные (ЭГДС) с взятием гастробиоптатов, гистологические, 
гистохимические, морфометрические и статистические, изучалась микрофлора кишечника на дисбактериоз (по методу Эштейн-Литвак и Вильшанской, 1968).

Биоптаты СО названных отделов желудка фиксировали в 10\% нейтральном растворе формалина и заливали в парафин, в последующем резали на роторном микротоме с толщиной гистологического среза не более 5 мкм и окрашивали: $1 \%$ раствором альцианового синего, гематоксилином Эрлиха и эозином в качестве материала для обзорного гистологического и полуколичественного морфометрического изучения; пилорический хеликобактер окрашивали азур-ІІ метиленовым синим по Гимзе (1998); дрожжевые грибы рода Candida верифицировали насыщенным спиртовым раствором тионина по Николя (1973); разные жизненные формы криптоспоридий (спороцисты, спорозоиты) окрашивали по ЦилюНильсену (1936); тучные клетки в срезах выявляли основным коричневым по Шубичу (1972). Результаты гистологического, гистохимического, бактериологического, паразитологического и микологического анализов биоптатов оценивали по процентной частоте встречаемости морфологического признака.

В каждом препарате определяли: гистологический тип хронического гастрита; активность патологического процесса, наличие атрофии желез в СО желудка; тип метаплазии и интраэпителиальную неоплазию (дисплазию) в СО желудка; тип рака желудка (интестинальный - кишечный) и диффузный; плотность воспалительного клеточного инфильтрата в собственной пластинке и очередность клеточной последовательности в воспалительном инфильтрате СО желудка; наличие кровоизлияний и полнокровие сосудов микроциркуляторного русла в собственной пластинке СО желудка, а также наличие пилорических хеликобактеров, дрожжевых грибов рода Candida и разных жизненных форм криптоспоридий на СО желудка [6].

Результаты исследования и обсуждение. Гистологически в 25 биоптатах слизистой оболочки фундального отдела желудка (СОФОЖ) чаще выявляли умеренную активность патологического процесса в 48,0\% и реже - минимальную и выраженную (36,0\% и 16,0\% соответственно). В СОФОЖ чаще выявляли умеренную атрофию фундальных желез в 44,0\% и минимальную атрофию - у 40,0\%, а выраженную только в 16,0\% случаев. В биоптатах ямочного эпителия СОФОЖ выявляли полную тонкокишечную метаплазию в 16,0\%. Дисплазия ямочного эпителия (неопределенная интраэпителиальная неоплазия) СОФОЖ встречалась у 8,0\% пациентов. Интестинальный тип рака желудка in situ из ямочного эпителия СОФОЖ обнаружен у одной пациентки (4,0\%). Плотность воспалительного клеточного инфильтрата в собственной пластинке межъямочных отделов СОФОЖ была у $40 \%$ пациентов была минимальной, у $24 \%$ умеренной и в $36 \%$ случаев - максимальной. В воспалительном инфильтрате СОФОЖ превалирующими клетками по мере убывания были: плазмоциты, лимфоциты, фибробласты, фиброциты, макрофаги, эозинофильные и нейтрофильные гранулоциты.

Кровоизлияния в собственную пластинку СОФОЖ разной степени выраженности встречались у $88 \%$ пациентов, из них в $60 \%$ умеренной и в $28 \%$ с минимальной степенью. Полнокровие сосудов микроциркуляторного русла (МЦР) в СОФОЖ было выявлено во всех исследуемых препаратах, из них у 68\% - умеренное полнокровие, выраженное и минимальное с одинаковой степенью (в 16\% случаев). Ишемию кровеносных сосудов МЦР в собственной пластинке СОФОЖ обнаруживали с частотой 8\%. Пилорический хеликобактер с частотой в (++) в СОФОЖ встречался у 40,0\% пациентов, в (+) - у $32,0 \%$ и $(+++)$ - в 28\% случаев. Разные жизненные формы криптоспоридий на СОФОЖ выявлены у 48,0\% пациентов, из них минимальное их количество было выявлено у половины пациентов, умеренное количество в 41,7 \%, а выраженная степень контаминации отмечалась лишь в 8,3 \%. Дрожжевые грибы рода Candida в СОФОЖ были выявлены в 44,0\% случаев с преобладанием минимальной степени контаминации СОЖ в 81,8\% и умеренная в 18,2\%. Хронический фундальный гастрит В ассоциированный с грибами рода Сandida представлен на рисунке 1.

При исследовании 47 биоптатов слизистой оболочки антрального отдела желудка (СОАОЖ), гистологически чаще выявляли умеренную активность патологического процесса в 51,1\%, выраженную активность - в 44,7\%, а минимальную активность только у 4,3\% пациентов. В СО этого отдела желудка чаще выявляли умеренную атрофию пилорических желез у $61,7 \%$, минимальную - у 29,8\%, а выраженную - только у 8,5\% пациентов. Фовеолярную гиперплазию ямочного эпителия СОАОЖ обнаруживали у $34 \%$ пациентов. Гистологическая картина хронического антрального хеликобактерного гастрита при контаминации криптоспоридиями представлена на рисунке 2. Интраэпителиальную неоплазию ямочного эпителия СОАОЖ разной степени выраженности была выявлена в 19,2\% случаев, из них II степени у 6,4\% наблюдавшихся лиц, а тяжелую дисплазию III степени - у 12,8\% пациентов. Рак in situ из ямочного эпителия СО АОЖ был диагностирован в 4,3\% случаев. Плотность воспалительного клеточного инфильтрата в субэпителиальных отделах СОАОЖ была высокой у 46,8\% пациентов, умеренной - у 31,9\% пациентов и минимальной - только у 21,3\% пациентов. При этом, в СОАОЖ, в воспалительном инфильтрате собственной пластинки по мере убывания в 55,3\% случаев превалировали плазматические, у 27,7\% пациентов обнаруживали лимфоциты, фиброциты, а эозинофильные гранулоциты - в 17 \% случаев.

Кровоизлияния в СОАОЖ обнаруживали в 85,1\% биоптатах, из них у 55\% были умеренными, а у $45 \%$ минимальными. Полнокровие сосудов микроциркуляторного русла (МЦР) в СОАОЖ было выявлено у 95,7\% пациентов. При этом минимальное полнокровие обнаруживали у 66,7\% человек, умеренное - у 26,7\% пациентов, а выраженное - у только у $6,7 \%$ пациентов. Ишемия сосудов МЦР в СОАОЖ встречалась только у 12,8\% пациентов. Пилорический хеликобактер в СОАОЖ был выявлен у 95,7\% пациентов. При этом минимальную степень обсеменения (+) выявляли у 17,8\%, умеренную $(++)$ у $55,6 \%$, а выраженную (+++) у 26,7\% случаев. Чаще на последней обнаруживали кокковые формы этих бактерий, реже - кокковидные и палочковидные их формы и еще реже эти бактерии выявляли в тройной ассоциации (кокки, палочки, спириллы). Криптоспоридии на СОАОЖ были выявлены только у 10,6\% пациентов. Контаминация СОАОЖ криптоспоридиями представлена на рис. 3. Грибы рода Candida на СОАОЖ были обнаружены у 36,2\% человек. При этом 


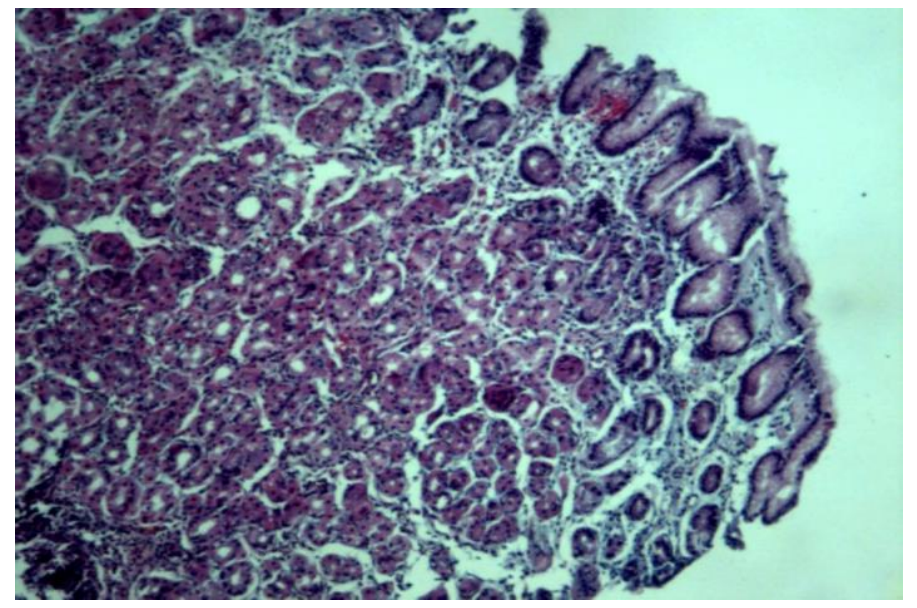

Рис. 1. Слизистая оболочка фундального отдела желудка. Хронический фундальный гастрит В. Грибы рода Candida на покровно-ямочном эпителии. Окраска гематоксилином и эозином. Ув. 240.

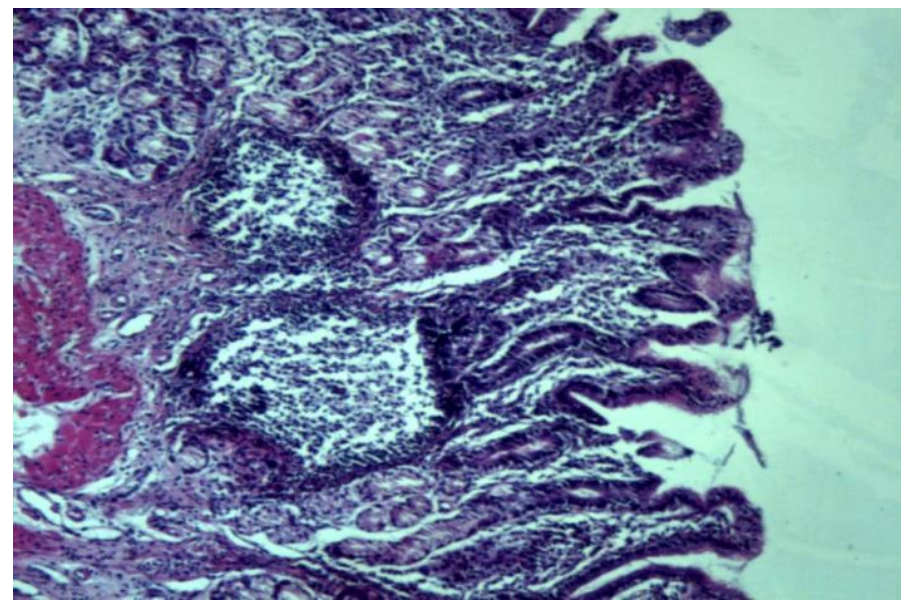

Рис. 2. Слизистая оболочка антрального отдела желудка. Хронический антральный гастрит В. Два лимфоузелка с герминативными центрами между антральными железами. Окраска гематоксилином и эозином. Ув. 240.

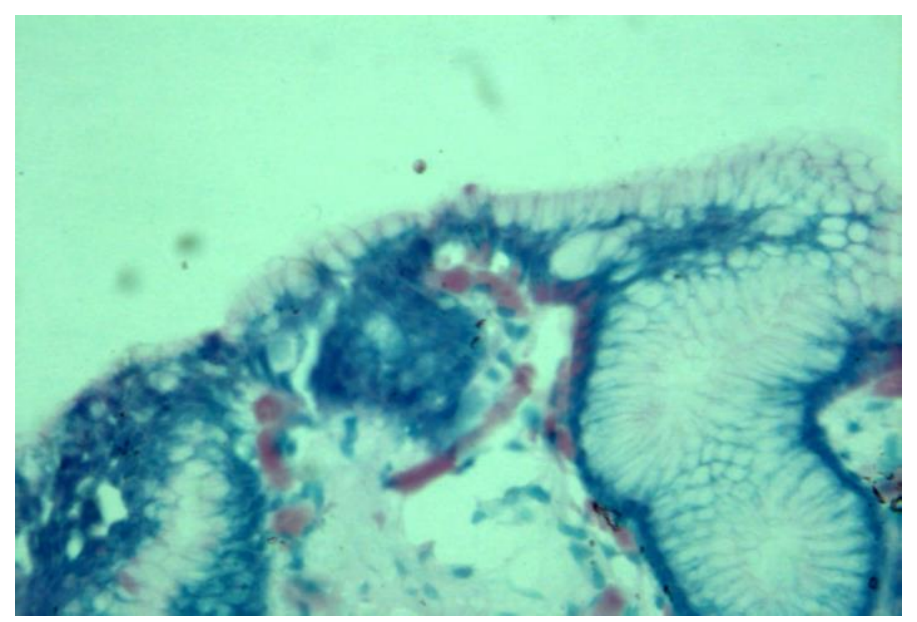

Рис. 3. Слизистая оболочка антрального отдела желудка. Хронический антральный гастрит В. Спороцисты находятся на покровно-ямочном эпителии. Окраска по Циль-Нильсену. Ув. 900. минимальная степень контаминации $(+)$ на СОАОЖ была выявлена у $82,4 \%$, умеренная $(++)$ - у $11,8 \%$, а выраженная (+++) у $5,9 \%$ пациентов.

В настоящее время считается доказанным и признанным мировым медицинским сообществом ведущая роль Helicobacter pylori как главной причины развития хронических воспалительных изменений в слизистой оболочке желудочно-кишечного тракта. Хронический НР - ассоциированный гастрит во всех случаях сопровождается специфическими морфрофункциональными изменениями СО разных отделов желудка и 12-типерстной кишки, свидетельством активности которых является мононуклеарная воспалительная инфильтрация в собственной пластинке СОЖ с превалированием в нем нейтрофилов, атрофических изменений главных желез c развитием кишечной метаплазии и дисплазии (неопределенной интраэпителиальной неоплазии) ямочного эпителия, что является на фоне генетической предрасположенности, стартовой площадкой к развитию неопластического процесса [7].

Как показали исследования последних лет, большинство хронических НР-ассоциированных гастритов, протекают в виде смешанного инфекционного патологического процесса с утяжелением течения основного заболевания [2-5; 8]. Проведенные в нашей работе исследования показали высокую степень обсеменения СО разных отделов ЖКТ пилорическим хеликобактером с характерными для него морфофрункциональными изменениями. Однако хорошо известно, что с прогрессированием патологического процесса, создаются условия для колонизации СОЖ другими микроорганизмами (условно-патогенными бактериями, грибами, простейшими, вирусами). Установлено, что условнопатогенные грибы рода Candida, являясь составной частью эндоэкологической среды человека, становятся причиной развития заболеваний, активируя свои патогенные свойства лишь при определенных условиях. Согласно многочисленным исследованиям, Candida albicans выявляется не менее чем в 30-80\% на поверхности неизмененной СО и области язвенных дефектов желудка. Провоцирующими факторами активации процесса могут являться применение антибиотиков, гипохлоргидрия желудка, сахарный диабет, злоупотребление алкоголем, ослаблением иммунной защиты, пожилой возраст и др. [16].

Анализ гистологических исследований биоптатов разных отделов желудка показал, что грибы рода Candida были выявлены в 44\% на СОФОЖ и $36,2 \%$ на СОАОЖ. Факторами, способствующими колонизации, были прием антибиотиков и ингибиторов протонной помпы в эрадикационных схемах при ассоциации с НР. При этом пациенты жаловались на диарею, вздутие живота, тошноту, астению, сниженный аппетит, изменение вкуса продуктов. При ЭГДС часто выявляли творожистый налет на языке, пищеводе. Чаще поражалось тело желудка в области атрофии и пилорической метаплазии тела желудка на фоне гипохлоргидрии. Полученные нами результаты выявили повышенный риск присоединения грибковой микрофрлоры при снижении кислотопродуцирующей 
способности желудка, о чем ранее указывали ряд исследователей [14, 18-20].

У пациентов с синдромом раздраженного кишечника на поверхностном и ямочном эпителии СО фундального и антрального отделов были выявлены криптоспоридии с частой 48\% и 19,1\% случаев (соответственно). Криптоспоридии являются облигатными внутриклеточными паразитами, способными поражать разные отделы пищеварительного тракта, преимущественно тонкий кишечник, с развитием диареи, обезвоживанием организма и снижением массы тела. При поражении криптоспоридиями слизистой оболочки желудка диареи может не быть. У пациентов с иммунодефицитом криптоспоридии способны поражать другие органы и системы, а у иммуннокомпетентных пациентов на фоне иммуносупрессивной терапии криптоспоридиоз чаще протекает с поражением кишечника [15]. Более выраженная колонизация криптоспоридиями СОФОЖ связана, скорее всего, с высокой кислотностью антрального отдела желудка и способностью разрушать ооцисты криптоспоридий, что было подтверждено паразитоскопическим исследованием биоптатов СО разных отделов желудка.

Заключение. Исследования разных отделов СОЖ у пациентов с СРК выявили в хронический хеликобактерный гастрит с более выраженной активностью патологического процесса в антральном отделе желудка, атрофическими изменениями главных желез, фовеолярной гиперплазией, неопределенной неоплазией I-II степеней, высокой плотностью клеточного инфильтрата с преобладанием в клеточном инфильтрате плазмоцитов, лимфоцитов, макрофагов. Криптоспоридии чаще выявляли в фундальном отделе желудка, а грибы рода Candida на поверхностном и ямочном эпителии. Патоморфологические изменения слизистой оболочки желудка зависели от локализации процесса, степени контаминации и наличия разных жизненных форм пилорического хеликобактера, тогда как криптоспоридии и грибы рода Candia (не инвазивные формы, а нашем случае) существенного влияния на морфологию слизистой желудка не оказывали.

\section{ЛИТЕРАТУРА:}

1. Червинец, В.М. Микрофрлора слизистой оболочки ульцерозной зоны пациентов язвенной болезнью двенадиатиперстной кишки / В.М. Червинец, В.М. Бондаренко, С.Н. Базлов // Журн. микробиол. - 2001.- №5. - C.12-15

2. Чернин, В.В. Болезни пищевода, желудка и двенадиатиперстной кишки: Руководство для врачей / В.В. Чернин. М.: ООО «Медицинское информационное агентство», 2010. - 528 c.

3. Щербаков И.Т., Леонтьева Н.И., Грачева Н.М., Щербакова Э.Г., Хренников Б.Н., Новикова Л.И. Действие хеликобактеров на слизистую оболочку разных отделов желудка //Инфекционные болезни. - Матер. 1 Ежегод. Всеросс. Конгр, по инфекционным болезням. - М., 2009. - том 7, приложение №1. - С. 239-240.

4. Леонтьева, Н.И. Значение дисбактериоза кишечника в течении хронических заболеваний желудочно-кишечного тракта, ассоциированных с Helicobacter pylori /Н.И. Леонтьева, Н.М. Грачева, И.Т. Щербаков // Инфекционные болезни. - 2010. - Том 8. - №4. - С. 83-85.

5. Леонтьева, Н.И. Морфологические изменения слизистой оболочки желудка при контаминации разными жизненными формами пилорических хеликобактеров /Н.И. Леонтьева, И.Т. Щербаков, Н.М. Грачева, Б.Н. Хренников, Э.Г. Щербакова, О.С. Партин // Российский медико-биологический вестник им. академика И.П. Павлова. - 2011. - №3. - С.13-17.

6. Аруин Л.И., Капуллер Л.Л., Исаков В.А. Морфологическая диагностика болезней желудка и кишечника. - М.: Tpuada $-X, 1998 .-483$ c.

7. Кононов, A.В. Helicobacter pylori-acсоциированные заболевания: интерпретация биопсий. Сб. научных трудов /А.В. Кононов /М. 2007. - С. 55-59.

8. Леонтьева, Н.И. Влияние разных форм пилорических хеликобактеров на морфологические изменения 8 слизистой оболочке желудка / Н.И. Леонтьева, И.Т. Щербаков, Н.М. Грачева, Б.Н. Хренников, Э.Г. Щербакова // Медицинский альманах, раздел Гастроэнтерология. - №2 (15), март, 2011. - С. 61-64.

9. Сергеев А.Ю., Сергеев Ю.В. Кандидоз: природа инфекции, механизмы агрессии и защиты, лабораторная диагностика, клиника и лечение. - М.: Триада -X, 2001. - 472 с.

10. Маев, И.В. Кандидоз пищевода /И.В. Маев, Г.А. Бусарова // Лечащий врач. - 2002. - № 6. - С. 44-50.

11. Шевяков, М.А. Диагностика и лечение кандидоза пищевода /М.А. Шевяков // Фарматека. - 2005. - № 7 (102). - С. 60-63.

12. Бурова, С.А. Современные представления о грибковой патологии пищеварительного тракта /С.А. Бурова // Лечащий врач. - 2005. - № 6. - С. 52-56.

13. Лесовой, В.С. Микозы пищеварительного тракта (Обзор) /В.С. Лесовой, А.В. Липницкий, О.М. Очкурова // Пробл. мед. микологии. - 2004. - Т. 6, № 2. - С. 19-21.

14. Баженов, Л.Г. Роль грибов рода Candida в микробиоценозе желудка при хеликобактериозе / Л.Г. Баженов [и др.] // Успехи мед, микологии. - 2003. - T. 1. - С. 8-9.

15. Чебышев Н.В., Сергиев В.П. Медицинская протозоология. Паразитические простейшие человека. М., ГЕОТАРмedua, 2012. - C.182-189.

16. Kroschinsky, F. Candidiasis in cancer patients: Epidemiology, diagnosis, prophylaxis and therapy / F. Kroschinsky, R. Naumann, G. Ehniger // Mycoses. - 1999. - Vol. 42 (suppl. 1). - P. 53-59.

17. Minoli, G. A prospective study on Candida as a gastric opportunistic germ / G. Minoli G. [et al.] // Digestion. - 1982. - Vol. 25. - P.230-235. 
18. Dromer, J.E. Enhanced immune responses in mice treated with penicillin-tetracycline or trimethoprim-sulfamethoxazole when colonized intragastrically with Candida albicans / J.E. Dromer, R.F. Hector // Antimicrob. Agents Chemother. - 1987. - Vol. 31. - P. 691-697.

19. Maraki, S. Prospective evaluation of the impact of amoxicillin, clarithromycin and their combination on human gastrointestinal colonization by Candida species / S. Maraki [et al.] // Chemotherapy. - 2001. - Vol. 47. - P. $215-218$.

20. Safdar, N. The commonality of risk factors for nosocomial colonization and infection with antimicrobial-resistant Staphylococcus aureus, Enterococcus, gram-negative bacilli, Clostridium difficile and Candida / N. Safdar, D.G. Maki / Ann. Intern. Med. - 2002. - Vol. 136. - N4. - P. 834-844.

\section{Авторская справка:}

1. Щербаков Иван Тимофреевич, ведущий научный сотрудник, доктор медицинских наук, ФБУН «Московский НИИ эпидемиологии и микробиологии им. Г.Н. Габричевского» Роспотребнадзора; 125212, Москва, ул. Адмирала Макарова, 10; (8495) 190-46-70; моб.8-962-920-01-32; e-mail: partinos@mail. ru.

2. Леонтьева Нина Ивановна, ведущий научный сотрудник, доктор медицинских наук, ФБУН «МНИИЭМ им. Г.Н. Габричевского» Роспотребнадзора; 125212, Москва, ул. Адмирала Макарова, 10. (8495) 190-46-70; моб. 8-926-50212-31; e-mail: leonteva-nina@yandex.ru.

3. Грачева Нина Михайловна профессор, доктор медицинских наук, ФБУН «Московский НИИ эпидемиологии и микробиологии им. Г.Н. Габричевского» Роспотребнадзора; 125212, Москва, ул. Адмирала Макарова, 10; (8495) 193425-45; моб.8-903-973-79-62; e-mail: partinos@mail.ru

4. Филиппов Валерий Семенович, научный сотрудник, ФБУН «Московский НИИ эпидемиологии и микробиологии им. Г.Н. Габричевского» Роспотребнадзора; 125212, Москва, ул. Адмирала Макарова, 10. (8495) 190-46-70; моб. 8-915111-52-39; e-mail: oritabdul786@mail.ru.

5. Виноградов Николай Алексеевич, доцент, доктор медицинских наук, ФГБОУ ВО РНИМУ им. Н.И. Пирогова Минздрава России; моб. 8-909-150 35-79; e-mail: n.a.vinogradov@mail.ru.

6. Филиппова Ольга Александровна, заведующая отд., врач-инфекционист, ГБУз «ИКБ №1» Департамента здравоохранения Москвы; 125367, Москва, Волоколамское шоссе, 63; моб. 8-915-111-52-29; e-mail: oritabdul786@mail.ru. 